Revista Iberoamericana. Vol. LXV, Núm. 186, Enero-Marzo 1999; 49-57

\title{
LA NOVELA DE LA REVOLUCIÓN MEXICANA Y LA REVOLUCIÓN EN LA NOVELA
}

\author{
POR \\ María del Mar Paúl Arranz \\ Universidad Europea de Madrid
}

Cuando se habla de "novela de la Revolución Mexicana" casi siempre empieza por discutirse la propia validez del concepto para terminar, a menudo, negándolo. Yo empezaré por negarlo porque, al igual que otros, también creo que hay novelistas de la Revolución (con todos los matices pertinentes), pero no una novela de la Revolución, no un género propiamente dicho. ${ }^{1}$ Ello, sin embargo, no invalida el hecho de que existen una serie casi infinita de obras que son fruto de una realidad histórica y que no desaparecen aunque pongamos en duda su carácter de novelas y hasta desestimemos que lo sean con rigor. Quizá lo único obligado es resaltar la diversidad y no caer en la trampa de intentar encajarla en un molde previo (desde luego ése sí, inexistente) o solaparla bajo los nombres de crónicas, memorias o reportajes. La etiqueta, pese a todo, no es un invento de la crítica, pues fue acuñada en la polémica de 1925 y luego insistentemente repetida a lo largo de los años treinta. No obstante, lo que la crítica sí ha hecho después ha sido sancionarla y agrupar sin mayor justificación bajo ese membrete todas las novelas de tema revolucionario, sin importar la época, los autores o las diferencias técnicas. Fue así como, al decir de algunos, la novela de la Revolución se convirtió en uno más de los mitos revolucionarios, pero cada vez se hace más claro que los rasgos formales que fueron señalados como distintivos no son tales, y técnicamente se puede asegurar que estas "novelas" tienen muy poco de innovadoras. Aunque los autores traten de escribir dentro de los amplios horizontes del realismo, estilísticamente pocas semejanzas existen entre Martín Luis Guzmán y Rafael F. Muñoz, o entre José Vasconcelos y José Rubén Romero, o incluso entre Gregorio López y Fuentes y Mauricio Magdaleno.

\footnotetext{
' Es el caso de Jorge Von Ziegler o de Felipe Garrido que la niegan taxativamente, como niegan los rasgos definitorios que críticos como Castro Leal le atribuyeron: perspectiva autobiográfica, carácter épico o fragmentación en cuadros y visiones episódicas, recurso éste manejado en otras obras independientemente del tema. Además, a juicio de Garrido, las novelas más brillantes de la Revolución no emplean esta manera de contar; por tanto, concluye: "Si las novelas de la Revolución escritas entre 1928 y principios de los años cuarenta tienen entre sí un aire de familia, no es tanto porque compartan un tema - aunque esto, por supuesto, al igual que el carácter autobiográfico de muchas de ellas, agudice las semejanzas-, sino porque corresponden a un mismo tiempo histórico; dicho aire de familia lo tienen también con muchas otras novelas de la época que no se ocupan de la Revolución" (844).
} 
A lo sumo, los autores que escriben en la década de los treinta coinciden en el cultivo del periodismo, en la fuente de sus lecturas, que proviene principalmente de la Unión Soviética, y en una práctica literaria que trata de seguir, según cada uno las entiende, las pautas dictadas por Ermilo Abreu Gómez y, más lejos, por Barbusse y otros teóricos marxistas. Pero para casi todos las cuestiones técnicas son secundarias y no falta quien cree, como Muñoz, que corregir los originales revela hipocresía (Carballo 348). Fuera de eso se acabaron las semejanzas. Resulta entonces que estamos ante un género que se define casi exclusivamente por su tema, lo cual no parece menos arriesgado a la hora de definirlo, puesto que si toda novela con remembranzas revolucionarias es virtualmente una novela de la Revolución, las posibilidades del género se hacen infinitas y los límites temporales absurdos. ¿Qué sentido tiene que esa misma crítica que adopta el criterio temático diga unas veces que la novela de la Revolución acaba con Al filo del agua, otras con La muerte de Artemio Cruz y aun otras con Los recuerdos del porvenir? ¿Cómo puede decirse que acaba lo que potencialmente no tiene fin? Por otro lado, tampoco encontramos una posición común en el tratamiento del tema, si acaso una actitud compartida: la del desencanto, pero eso nos daría un criterio nuevo de clasificación que francamente me parece poco literario. Una vez más, la diversidad se resiste a ser acotada. En definitiva, sea cual sea el rasgo elegido para definirlas, ninguno es explícitamente diferencial.

Pues bien, creo que todo ello sólo es explicable porque la "novela de la Revolución" (que despertó desde muy pronto gran interés, sobre todo entre los estudiosos norteamericanos) ha sido objeto de análisis excesivamente apegados a la propia ideología revolucionaria. En el principio esta narrativa encarnaba para sus promotores la épica del pueblo mexicano, y sus artífices no eran tanto novelistas como cronistas; por consiguiente, más que una literatura se estaba elaborando una epopeya, un testimonio que el futuro sabría apreciar: quien quisiera conocer con lujo de detalles qué fue la Revolución tendría que ir a los escritores, a Azuela, a López y Fuentes, a Muñoz sobre todo. Esta dimensión documental fue reconocida desde el principio, sin duda para reforzar su valía, y fue incorporada por la crítica posterior, que no supo ver que estábamos ante manifestaciones literarias, y en cuanto tales, obras intrínsecamente falsas. ${ }^{2}$ En consonancia, se resaltaron unos rasgos estilísticos que pretendian confirmar ese carácter historicista y desde entonces, según apunta Aguilar Camín con acierto: "las páginas de estos autores han sido [...] a la vez un hecho literario y una lección de historia, una mitología y una hermenéutica, la trama novelística y la verdad historiográfica" (102). Demasiados atributos, no cabe duda, pero fue tal el éxito de este análisis que nuestra imagen de la Revolución Mexicana se debe en gran parte a los novelistas y no a los historiadores.

A partir de ahí se ha llegado a imponer, por lo general, una lectura "canónica" de la "novela de la Revolución" que pretende salvar sus muchas contradicciones implícitas.

\footnotetext{
${ }^{2}$ Por supuesto, hay excepciones. John Rutherford, que para casi todo lo demás se mantiene fiel a los criterios señalados, advertía de este peligro cuando decía que "las novelas escritas después de 1925 , no son fidedignas como fuentes documentales de la historia social de la revolución mexicana, a pesar del aparente realismo de muchas de ellas. Su forma y su presentación documentales no son más que otras tantas estratagemas novelísticas, y de ninguna manera se puede garantizar que sus páginas contengan informes verídicos sobre la Revolución" (86).
} 
Porque ¿cómo entender que fueran los antiguos partidarios de las facciones revolucionarias o los fervientes militantes del learismo ${ }^{3}$ los que hablaran del fracaso de los ideales, de la corrupción de los políticos, de la manipulación de las masas, de traiciones y de violencia a mansalva? Y ¿cómo entender que esa literatura crítica por excelencia conquistara los beneplácitos de la política oficial? ¿Estábamos ante un Estado tan generoso y tolerante que admitía la discrepancia hasta los extremos de aceptar de buen grado que los novelistas dudaran de su legitimidad? ${ }^{4}$ Para resolver la aparente paradoja a menudo se ha propuesto una doble lectura: por un lado está la realidad narrada, el bajo mundo, el "así fueron las cosas"; por otro, el plano abstracto en el que la Revolución es una suma de aspiraciones, el "así deben ser" y así serán, cuando triunfe. En ese momento la barbarie se trocaría, a través de la justicia, en medio civilizado de convivencia. De este doble plano de lectura resulta que el pesimismo de las novelas nunca alcanza al futuro - pues los finales quedan generalmente abiertos-y simbólicamente aparece alguna señal de esperanza. Se puede entonces concluir que no son pesimistas. Pero acudir a supuestos subliminales, que si bien son ciertos en algunas obras son negados tajantemente por otras, no resuelve definitivamente el problema. Y tampoco se resolverá si nos dejamos arrastrar por la idea de que se produce un género a partir de la revolución sólo para elaborar su épica, ni con endebles argumentos de justificación como, por ejemplo, el que utilizaba José Alvarado: "estas obras fueron producidas en circunstancias especiales de la Revolución, cuando todo parecía que iba a fracasar, cuando el camino no estaba lo suficientemente claro. Esta, tal vez, sea la causa de sus perfiles: parecen la crítica de un intento fracasado, quizá por esta misma circunstancia" (El popular, 1939). El argumento sería válido si hubieran sido escritas poco después del estallido revolucionario, pero no veinte años después. Por muy confusas que estuvieran las cosas, el presidente Plutarco Elías Calles había establecido ya en los años veinte los soportes básicos, tanto políticos como ideológicos, del Estado mexicano. ¿Por qué ese empeño entonces en disfrazar lo que era simple y puro desencanto?

Pero recuperemos la cronología y veamos si los textos de la época nos dan alguna luz sobre los interrogantes planteados. A pesar de que las obras de temática revolucionaria podían contarse por decenas, a mediados de la década de los treinta comienza a extenderse la idea de que la auténtica novela de la Revolución aún no se había escrito. ${ }^{5}$ Hay incluso

\footnotetext{
' La LEAR, Liga de Escritores y Artistas Revolucionarios, fue una organización que se constituyó prácticamente como un sindicato. Sus dirigentes impusieron durante el cardenismo unas pautas culturales basadas en el realismo socialista.

4 "La función del Estado mexicano como sostén y protector de la cultura muestra una paradoja no exenta de belleza: si otros Estados pagaban a los artistas que les proporcionaran un mito y una genealogía, el nuestro los reúne para hacer el registro de su descomposición y el final rito fúnebre" (Alfredo García, "Del crítico como un confabulado").

${ }^{5} \mathrm{He}$ aquí la mención de algunas de las publicadas: El águila y la serpiente y La sombra del caudillo, de Guzmán; La revancha, de Agustín Vera; Héctor, de Jorge Gram; El señor diputado, de Diego Arenas Guzmán; Vámonos con Pancho Villa, de Rafael F. Muñoz; La asonada, de José Mancisidor; Cartucho, de Nellie Campobello; Campamento, Tierra y Mi general, de Gregorio López y Fuentes; Apuntes de un lugareño y Desbandada, de José Rubén Romero; La virgen de los cristeros, de Fernando Robles, entre un largo etcétera. El mayor contingente se produce entre los años de 1930 y 1937.
} 
quienes hablan de "brotes esporádicos" (Gómez Maganda, El Nacional, 1935). Desde luego, al margen de las exageraciones y de las posibles recriminaciones, conviene que nos detengamos a averiguar qué fallas advierten sus más fïrmes defensores y qué es lo que le demandan. ¿Qué tipo de novela querían si ésta cumplía aparentemente el requisito de su compromiso con la historia y también con esa claridad al alcance de todos, que debía ser norma del arte nuevo, revolucionario y socialista? En primer lugar le reprochan su excesivo cuidado en reflejar la violencia y la crueldad de la Revolución: "Ha prevalecido casi siempre entre sus cultivadores, una irresistible inclinación a lo francamente macabro, prefiriendo los datos desnudos del episodio a la interpretación de las almas y el ambiente", dijo un comentarista anónimo. ${ }^{6}$ Les preocupaba, pues, que esta literatura - la más traducidaestuviera creando en el extranjero una imagen salvaje del país y oscureciendo además los logros conseguidos:

Los mexicanos, testigos a veces y a veces actores en los hechos recientemente pasados, nos horrorizamos en verdad al leer las narraciones de estos escritos de la post-revolución, para los cuales el movimiento popular no fue sino un teatro en donde el forajido actuó, delante de un escenario púrpura, desde el cual sembró el crimen y la ignominia y nos extrañamos de no ver nunca a través de sus escritos la figuras de los legisladores, de los hombres de estudio o de aquellos guiadores de multitudes tras de cuyo honrado programa fue todo un pueblo lleno de fe (Rojas González, Crisol, 1934).

Pero a estas alturas podemos preguntarle a Francisco Rojas González (que escribe, dicho sea de paso, La negra Angustias en 1944, reflejando esa misma atmósfera violenta) a qué legisladores que no tuvieran canana y pistola se refiere, a qué hombres de estudio o guiadores de multitudes que no estuvieran encerrados en la torre de marfil alude, qué programa honrado siguió ese pueblo lleno de fe, si se había asesinado a Zapata precisamente por honrado y por tener programa. Pero aun así, no le faltaba razón al escritor, porque quienes estaban instigando la imagen salvaje de México "diario hacen alarde de revolucionarismo y viven, muchos de ellos, a costillas de un gobierno que según sus relatos fue encumbrado por pícaros y asesinos". Lo que en realidad parecían decirles los representantes de la ortodoxia a estos novelistas es que la ideología revolucionaria exigía al menos cierta coherencia. Por eso, era un contrasentido que se diera el título de novelistas de la Revolución a aquéllos que no escatimaban ataques a la hora de juzgarla:

Se ha creído que por el solo hecho de relatar acontecimientos de la pelea insurrecta, se les puede considerar revolucionarias en sí mismas, lo que equivale a pensar que la Revolución consiste simplemente en la lucha armada, en el vivac o en el golpe político. Como si la Revolución no fuera, justamente, el sentido de los acontecimientos y no los acontecimientos mismos. Los hechos puros, militares o políticos, pueden ser absolutamente iguales en una Revolución o en una contrarrevolución. Las aventuras bélicas, las peripecias de una campaña, con todo su aspecto dramático, con toda su intensidad vital, en su puro acontecimiento no se distinguen. Lo que las diferencia es su significado. En Los de abajo y en La sombra del caudillo, falta ese sentido que las haría obras revolucionarias (Alvarado, El popular, 1939).

\footnotetext{
6 “Alusiones a la literatura de la Revolución Mexicana”. El Nacional, 17 de noviembre, 1935.
} 
Que nadie se llame a error, por tanto: la novela de la Revolución no es la novela revolucionaria. Para hacer posible esa novela es preciso superar, siguiendo este razonamiento, el relato de la fase bélica, que no ha sabido llegar a la hondura íntima y universal del hombre mexicano ni plasmar su profunda interrelación con la tierra que habita. ${ }^{7}$ Los novelistas se quedaron, según Andrés Henestrosa, a mitad de camino en ese proceso, aunque apenas deja entrever la causa: "Creer que el manantial se inicia y acaba allí donde brota, ha sido error de los que se han enfrentado, sin adhesión, a nuestras luchas sociales. Por eso se quedan en la cáscara, en el espectáculo, en lo exterior, donde logran éxitos rotundos" (El Nacional, 1939). En esa falta de adhesión a "nuestras luchas sociales" estaba probablemente la explicación de la ambigua actitud de los novelistas de la Revolución, o, dicho de otro modo, el reproche de "no haber captado el sentido de la Revolución" era simplemente un eufemismo con el que se estaba encubriendo su falta de compromiso con la ideología revolucionaria. Los marxistas, en cambio, lo vieron con absoluta claridad:

La tendencia proletaria pudo haberse manifestado brillantemente en la novela de la Revolución Mexicana. Pero nuestra novela revolucionaria es tan burguesa como la misma producción vanguardista. En primer lugar, hay que notar su falta de ideología, su inmensa desorientación. Luego, este género literario ha huido cobardemente de la realidad actual que interesa analizar y estudiar, si se quiere producir una obra honrada. Ha huido de esta realidad para refugiarse en el anecdotismo de la lucha revolucionaria. El espectáculo de los ahorcados. Los excesos naturales del pueblo que se sacude el yugo de la dictadura. Pancho Villa exhibido ante el regocijo reaccionario... Todo lo que halaga al histerismo de la burguesía nacional y mundial (Turrent Rozas, "Hacia una literatura proletaria", 1932; citado por Rutherford 85).

Rubén Salazar Mallén, por su parte, se limita a hacer una crítica formal y no de contenido. Considera que para los escritores de la Revolución no importa la literatura "ni si tiene una posición filosófica, basta con consignar datos que en ocasiones ni siquiera se analizan". Los matices de este "género hacia fuera" o "desde fuera" —así lo llama él— van desde preservar cierto afán literario, pese a todo, a la proclama más panfletaria y extraliteraria (El Universal, 1937).

Aunque consideremos lo difuso de los ideales revolucionarios - que no nacen con la lucha, sino como un proceso posterior de ideologización del Estado- hay que acudir al origen de los narradores para encontrar las claves de sus respectivas posiciones. Hasta ahora sólo se ha aludido de forma recurrente a la infranqueable posición de "pequeña-burguesía" desde la que narran, a su condición de minoría ilustrada, a su ligazón inmediata con un pasado (el porfirismo) que de repente quiere convertirse en prehistoria. En sus obras nos dan instantáneas de la Revolución, pero se escamotea por lo general el contexto social de la lucha de las facciones y el análisis de las causas que llevan a situaciones de hecho. Por eso merecieron los más duros ataques de José Revueltas, que se indigna con su falso realismo. Sólo salva de su crítica a Guzmán y Muñoz pues son los únicos que "toman la realidad sin prejuicios, sin tesis previas, sin nociones metafísicas - rojas o blancas-sobre el Bien y

${ }^{7}$ Esto lo expresa el mismo Magaña Esquivel en sendos artículos: "La novela mexicana" y "Tres novelistas de México". 
el Mal". Su obra es, por esa razón, "profundamente realista y por ende revolucionaria y dialéctica". ${ }^{8}$ A mi modo de ver, ni siquiera ellos hacen lo que Revueltas cree, aunque Guzmán tal vez fue más hábil que los demás, como excelente escritor que era, en interpretar y supeditar la realidad a sus prejuicios.

No vamos a negar a los novelistas, en cualquier caso, lo que de cierto contienen sus ataques, pero es obvio que con su visión maniquea redujeron la Revolución a una encarnizada disputa por el poder. Sin embargo, no fueron reduccionistas ni escépticos por falta de comprensión del fenómeno, sino por un desacuerdo de "clase" que a veces afloraba inconscientemente y que otras trataban de combatir con su mejor voluntad y a menudo sin ningún éxito.' A la postre, el carácter de su censura es eminentemente moral, porque entienden que ése es también el principal fracaso del movimiento revolucionario.

Por otra parte, se ha dicho con frecuencia que el pueblo es el protagonista indiscutible de esta narrativa, pero, como también advertía Revueltas, la mayoría de estos escritores tiene la tendencia a considerar al pueblo como un dechado de virtudes. Son escritores "de lo más bienintencionados", decía, que desean sinceramente el mejoramiento del pueblo pero que sólo pretenden mostrar que lo conocen (Letras de México, n. 128). Lo cierto es que nunca vieron en el pueblo un agente del cambio. Manipulado por caudillos sin escrúpulos, para quienes era simple medio de conquistas políticas, el pueblo parecía obtener exclusivamente en el saqueo el triunfo de su particular revolución. Ejemplos entresacados al azar lo confirman:

Ellos mismos no sabian a punto cierto qué quería la Revolución, pero cada cual tenía sus motivos de queja y sus deseos de una situación mejor. Sus odios, sus deseos de venganza, sus anhelos de mejoramiento económico; todo creían poderlo satisfacer (Rafael F. Muñoz, en Castro Leal I 696).

Entre las mútliples facciones revolucionarias no caben distingos, o al menos la masa no es capaz de hacerlos; se mueve por inercia, como la piedra que arrojada al fondo de un cañón ya no puede pararse:

Era cierto que si la revolución seguía, ellos tendrían que ponerse de parte de alguno de los bandos contendientes, porque de lo contrario los tratarian como enemigos. Así pues, había

\footnotetext{
* José Revueltas emprende su crítica desde su concepto de realismo -realismo crítico lo llama él-, contra el que atentan los más señalados novelistas de la revolución. Véase su artículo "La novela, tarea de México". (Letras de México n. 128). En otro lugar hablaba de "su chabacanismo político y su espantosa retórica" y añadía que los escritores de la Revolución eran precisamente "los representantes literarios de una revolución que no se define aún a sí misma; de una revolución abigarrada, de campesinos trágicos y políticos desenfrenados; de una revolución donde ha podido caber hasta don Mariano Azuela; de una revolución con minúscula, en una palabra" (Visión del Paracutín 256).

${ }^{9} \mathrm{De}$ lo primero Jorge Ruffinelli da numerosos ejemplos a propósito de Azuela en su libro Literatura e ideologia: el primer Mariano Azuela (1896-1918). Creo que su análisis de este autor es perfectamente aplicable al resto de los narradores de la Revolución. Dessau en La novela de la Revolución mexicana pone, por su parte, al descubierto los conflictos insolubles en que desembocan algunas obras, cuando los autores tratan de adoptar una visión mas cercana al marxismo a la hora de interpretar los hechos.
} 
que seguir adelante, había que empuñar nuevamente las armas para pelear por quién sabe qué causa que ignoraban, pero que para ellos era de vida o muerte. Había que volver a los días de lucha, de asechanza y matar o resignarse a perecer... Aquello no era la defensa de un ideal, sino el instinto de conservación (Agustín Vera, en Castro Leal I 834).

Incluso en los autores cuya crítica abarca también a la propia clase (es el caso de Magdaleno en El resplandor o de López y Fuentes en Mi general), la óptica popular no está lograda. Saben que la revolución no la va a decidir el pueblo. Ésta es una certeza que obtienen de la inconsciencia en la que vive ese pueblo y del conocimiento de los entresijos de la lucha, por eso pueden utilizar la ironía para desenmascarar a los falsos idealistas o a los oportunistas políticos y de paso advertir de los peligros del caudillismo:

La revolución parecía olvidarse que las aspiraciones de los militares al poder público han sido la causa de todas nuestras guerras intestinas y que la lucha que se iniciaba era precisamente contra otro despótico militarismo que, por una torpe transacción, se había dejado en pie, después del triunfo de Madero (Romero, en Castro Leal II 124).

En definitiva, el populismo de la novela de la Revolución fue tan convencional, interesado e inoperante como el que exhibía el poder, era uno más de los ingredientes necesarios, de acuerdo al "patrón" establecido por Azuela, para confeccionar una novela "tipo" que sería leída de buen grado por una clase media sensibilizada. Para ella y no para ese ejército de "desarrapados" se preparaban las estructuras modernizadoras que cuajarían en los años cuarenta y que la literatura tarde o temprano debería reflejar. Villaurrutia, miembro de los Contemporáneos y situado en las antípodas de planteamientos semejantes, veía esto curiosamente con una claridad meridiana: "El tipo de novela que necesitaría ahora México sería la novela de la clase media que, además, la forman precisamente los devoradores de novelas"(Capistrán 19-20).

Pese a todo, el apoyo institucional con que contaron los novelistas de la Revolución desde el principio, y en particular en la década los treinta, se justifica por varios factores. En primer lugar, mantuvieron viva la historia del país y ayudaron a fomentar el intenso nacionalismo de la ideología revolucionaria, como lo habían hecho antes los muralistas y lo harían después los cineastas. El nacionalismo literario, por su parte, podía exhibir los frutos de la búsqueda de la "mexicanidad". En segundo lugar, al centrar la acción de sus novelas en un periodo anterior aún más caótico y desastroso, desviaron la atención de los problemas contemporáneos. En tercer lugar, las novelas más negativas se escriben durante el cardenismo, y ello porque el régimen se abrió a que circularan ciertas corrientes críticas. Todavía las discrepancias entre los diferentes sectores y dirigentes eran admisibles. Los ataques, pues, se producen cuando podían formar parte de un proyecto revolucionario en marcha. No olvidemos que Cárdenas define el concepto de Revolución Mexicana como "un indivisible conjunto de aspiraciones populares que no se estanca, sino que vive en orgánico movimiento de renovación" (Cabrera 335), y que entre sus objetivos estaba construir un Estado en el que cupieran todos, aunque algunos, claro está, en los penales de las islas Marías.

Desde otros puntos de vista, esta narrativa representa el fracaso de la invención en la literatura. La Revolución brindó a una serie de personas con inquietudes literarias la 
oportunidad de escribir sobre un tema cuyo interés estaba garantizado y cuyos perfiles formales habían sido dados por Mariano Azuela. Pero si tenemos en cuenta la cantidad de autores de una sola obra y que los otros, cuando consideraron agotado el material, dejaron de escribir "novelas", aceptaremos con cautela su propia condición de novelistas. Me atrevo a pensar que de no haber existido el movimiento revolucionario de 1910, la mayoría se hubiera dedicado exclusivamente al periodismo o al desempeño de sus respectivas carreras. Quizá por eso seguimos hablando de "novela de la Revolución Mexicana" y no de novelistas de la Revolución. Incluso sus nombres, salvo excepciones, forman parte de un inventario colectivo. Se los ha incluido en un grupo porque sólo agrupándolos podía mencionarse a todos.

La narrativa posterior, sin embargo, se distinguirá por el uso de diferentes técnicas que transforman en cada caso el material anecdótico básico en una experiencia artística (véase Bruswood), no importa el tema de que se trate. El novelista recuperará así el papel de creador de realidades, aunque parta de la historia para construirlas. Hasta Samuel Ramos, desde los ámbitos de la filosofía, afirmaba en un artículo de 1940 la absoluta libertad del artista para manipular la realidad y advertía que cuando la realidad se hace objeto del arte se convierte en otra cosa (Letras de México, n. 15). Será a partir de esta fecha en la que por fin la invención, liberada en gran parte de las viejas servidumbres que la sometían a la búsqueda de la identidad nacional, podrá abrirse paso sin prejuicios.

\section{BiBLIOGRAFIA}

Aguilar Camín, Héctor. Saldos de la Revolución: cultura y política de México. México: Nueva Imagen, 1982.

Alvarado, José. "La novela de la Revolución". El Popular (13 de septiembre de 1939).

Anónimo. "Alusiones a la literatura de la Revolución Mexicana". El Nacional (17 de noviembre de 1935).

Brushwood, John, S. "Periodos literarios en el México del siglo XX: La transformación de la realidad". Aurora Ocampo, La crítica de la novela mexicana contemporánea. México: UNAM, 1981. 157-173.

Cabrera, Luis. Veinte años después. México: Botas, 1937.

Capistrán, Miguel. "Textos de Villaurrutia". Revista de Bellas Artes 7 (1966): 5-36.

Carballo, Emmanuel. Protagonistas de la literatura mexicana. México, Ediciones del Ermitaño, 1989.

Castro Leal, Antonio. La novela mexicana de la Revolución. II vols. México: Aguilar, 1969.

Dessau, Adalbert. La novela de la Revolución Mexicana. México: Fondo de Cultura Económica, 1972.

García, Alfredo. "Del crítico como un confabulado". La Gaceta del Fondo de Cultura Económica 240 (diciembre, 1990): 56-57.

Garrido, Felipe. “¿Revolución en las letras?” Revisia Iberoamericana LV/148-149(1989): 841-845.

Gómez Maganda, Alejandro. "La Revolución, el Arte y la Literatura". El Nacional (11 de marzo de 1935). 
Henestrosa, Andrés. "La Revolución Mexicana y su literatura". El Nacional (1 de febrero de 1939).

Muñoz, Rafael F. Vámonos con Pancho Villa. Antonio Castro Leal, La novela mexicana de la Revolución. II vols. México: Aguilar, 1969. 691-778.

Ocampo, Aurora. La critica de la novela mexicana contemporánea. México: UNAM, 1981.

Ramos, Samuel. "Arte y realidad". Letras de México 15 (15 de marzo de 1940).

Revueltas, José. "La novela, tarea de México". Letras de México 128 (15 de octubre de 1946).

"Sobre Juan de la Cabada". Visión del Paracutín, vol. 24. México: ERA, 1983.

Rojas González, Francisco. "Sobre la novela de la post-revolución", Crisol 65 (mayo, 1934).

Romero, José Rubén. Apuntes de un lugareño. Antonio Castro Leal, La novela mexicana de la Revolución. II vols. México: Aguilar, 1969. 53-139.

Ruffinelli, Jorge. Literatura e ideología: el primer Mariano Azuela (1896-1918). México: La Red de Jonás, Premia Editora, 1982.

Rutherford, John. La sociedad mexicana durante la Revolución. México: Editorial El caballito, 1978.

Salazar Mallén, Rubén. "La prosa en México". El Universal (9 de septiembre de 1937).

Vera, Agustín. La revancha. Antonio Castro Leal, La novela mexicana de la Revolución. I vol. México: Aguilar, 1969. 813-920.

Von Ziegler, Jorge. "Novelistas o novela de la Revolución Mexicana". Hora Crítica. México: Premia Editora, 1988. 7-11. 
